\section{Uma etnografia de modos de "fazer justiça"}

Lucía EILBAUM. "O Bairro Fala”: conflitos, moralidades e justiça no conurbano bonaerense. São Paulo, Hucitec/Anpocs, 2012. 448 páginas.

\section{Leticia Carvalho de Mesquita Ferreira}

Moradores de Los Pantanos, região do chamado conurbano bonaerense, na província argentina de Buenos Aires, o casal Marisa e Carlos tinha cinco filhos. Os caçulas eram um casal de gêmeos de 8 meses, Rodrigo e Sabrina, nascidos prematuros. Carlos trabalhava vendendo roupas e Marisa era dona de casa.

A vida doméstica de Marisa e Carlos tornou-se, em dezembro de 2007, objeto de um processo instaurado no sistema de justiça criminal da província de Buenos Aires. Uma denúncia envolvendo o casal chegou à Unidad Fiscal de Instrución K (UFI K), uma das repartições daquele sistema encarregadas de investigar crimes ocorridos em uma área delimitada do conurbano. Segundo a denúncia, Rodrigo falecera e sua irmã gêmea, Sabrina, estaria severamente desnutrida. Marisa e Carlos seriam responsáveis tanto pela morte no menino, como pelo estado da menina, tornando-se, por isso, "imputados" por "abandono de pessoa" em um processo criminal.

Entre os diversos procedimentos que constituíram a fase de instrução do processo, destacou-se o depoimento de Marisa na UFI K. Procurando defender-se de algo que se apresentava como mais que uma suspeita, Marisa respondeu a uma das perguntas que lhe foram dirigidas pela promotora da UFI com os seguintes dizeres: "o bairro fala". Segundo Marisa, seus vizinhos e familiares produziriam versões e acusaçõos intrusivas e falsas a respeito de sua vida doméstica que seriam espalhadas pelo "bairro" na forma de rumores, fofocas e dizeres que ela tentava explicar, condensar e contestar através da expressão "o bairro fala".

A expressão de Marisa, que aparece de diferentes formas em muitos registros, processos e encontros constitutivos do cotidiano de órgãos do Judiciário da província de Buenos Aires, dá título à obra "O Bairro Fala": conflitos, moralidades e justiça no conurbano bonaerense. O livro é fruto da tese de doutorado de Lucía Eilbaum, defendida no Programa de Pós-Graduação em Antropologia da Universidade Federal Fluminense (UFF) e, por sua excepcional qualidade, premiada pela edição 2011 do Concurso Brasileiro Anpocs de Obras Científicas e Teses Universitárias em Ciências Sociais. A autora já havia recebido diferentes prêmios por sua dissertação de mestrado (Los casos de policía en la justicia federal argentina: el pez por la boca muere, publicada em 2008), e a distinção de "O Bairro Fala" vem não apenas confirmar, mas também sublinhar sua rigorosa e sensível dedicação à produção de etnografias. Isto porque seus trabalhos explicitam e exploram ao máximo o sentido mesmo do que seja etnografia: não simplesmente um método de pesquisa, nem tampouco um tipo de texto, mas sim um modo de produção de conhecimento que é, por princípio, situado e relacional, comprometido com a explicitação de suas condições de produção, dotado de forte vocação comparativa e, por todas essas características, força motriz dos debates teóricos no campo da antropologia.

Produto de trabalho de campo intensivo realizado na referida UFI K, onde foi instaurado o processo envolvendo Marisa e Carlos, "O Bairro Fala" tem por objeto as formas de administração de justiça no conurbano bonaerense. O livro decifra as dinâmicas de interação entre os procedimentos formais que guiam a condução de processos criminais na justiça do conurbano e outros elementos insuspeitados, determinantes não apenas do desfecho desses mesmos processos, mas também de cada passo de seu percurso - a investigação criminal, a produção e a interpretação de "provas", a tomada de decisões ou, ainda, as fendas, os entreatos e os intervalos entre essas etapas. Através de casos, rotinas e diálogos escolhidos com precisão cirúrgica para constar do livro, Eilbaum revela que histórias de vida, ideologias políticas e posiçōes institucionais e sociais de agentes judiciais, assim como a reputação dos envolvidos e a natureza dos conflitos investigados, são matéria-prima fundamental de modos de "fazer justiça" na província de Buenos Aires. Um dos grandes méritos do livro, porém, é que a autora não apenas explicita a intervenção de tais elementos na condução de processos criminais, como também (e principalmente) esmiúça e expli- 
ca de que modo essa intervenção se dá - isto é, através de que mecanismos e vozes cada um deles se faz ouvir e assentar em depoimentos, registros e outros procedimentos judiciais.

Ainda que se fundamente, sobretudo, na observação do cotidiano da UFI K, a etnografia de Eilbaum se vale também de ricas entrevistas com pessoas vinculadas à administração de justiça na província de Buenos Aires (promotores, defensores públicos e advogados, secretários e juízes), da leitura sistemática de processos criminais e da observação e participação em audiências de julgamento (juicios). Somando-se a todo esse material, é determinante a perspectiva comparativa que atravessa o livro, tributária tanto do diálogo direto com outras etnografias, como da já consolidada experiência de pesquisa e interlocução da autora com a produtiva rede de pesquisadores a que pertence. Dedicados a análises de práticas de administração institucional de conflitos, tais pesquisadores encontram apoio no Instituto de Ciência e Tecnologia InEAC, sediado na UFF, sobre cuja formação e extensão se detém o antropólogo Roberto Kant de Lima no prefácio de "O Bairro Fala". À intensidade de diálogos dessa rede, à perspectiva comparativa que ela alimenta, mas certamente também à consciência da força do cotidiano e da singularidade das interações que observou na UFI K, deve-se outro dos grandes méritos do livro: a responsabilidade de não produzir generalizações vazias em relação às formas de "fazer justiça" vigentes no conurbano bonaerense.

Insistindo de forma metódica na importância de se considerar as interaçôes, os agentes, os tipos de conflito e os interesses específicos constitutivos de cada processo a que se refere, a autora expõe a força do cotidiano no contexto institucional e social em que realizou sua pesquisa - algo que distingue a administração de justiça em Los Pantanos de outras modalidades de atuação, já descritas em etnografias, características de órgãos do Judiciário argentino. $\mathrm{O}$ cotidiano, como mostra a autora, é determinante tanto dos conflitos administrados judicialmente na província de Buenos Aires, quanto da maneira como essa administração se dá. Na UFI K, afinal, "eram recebidos e tratados conflitos produto de relaçôes cotidianas, em âmbitos sociais cotidianos - 'o bairro' - e para cujo tratamento eram disponi- bilizados procedimentos cotidianos para os agentes judiciais" (p. 379).

Não obstante, além da especificidade do papel desempenhado pelo cotidiano no contexto pesquisado, e talvez justamente pela perspicácia da autora em apreendê-lo, "O Bairro Fala" apresenta ainda uma perspectiva inovadora em relação a abordagens já estabelecidas de formas de atuação do Poder Judiciário. $\mathrm{O}$ trabalho de campo permitiu a Eilbaum questionar a ênfase, consolidada na literatura antropológica, naquilo que distancia o Judiciário da sociedade. Há tempos essa opção analítica tem levado pesquisadores a privilegiar "o caráter objetivante e despersonalizado dos mecanismos de administração de justiça, dentre os quais predominam a expropriação do conflito pelo Estado, a lógica do sigilo, a predominância da escrita e de uma linguagem formalizada, esotérica e especializada” (p. 26). A autora, entretanto, prioriza o oposto: não o que demarca fronteiras supostamente rígidas entre Judiciário e sociedade, mas aquilo que os conecta, trespassando e revelando a permeabilidade de sua separação.

Duas categorias nativas chamaram a atenção da autora durante o trabalho de campo e tornaram-se, por sua relevância no cotidiano da UFI K, eixo condutor do livro e base de sustentação dessa inovadora perspectiva analítica: o "bairro" e a "crença". Acompanhando os sentidos, os usos e os papéis desempenhados ora pelo "bairro", ora pela "crença", e ora pela articulação entre ambos em situações específicas, Eilbaum logra explicitar as formas por meio das quais valores e interesses de pessoas envolvidas em processos criminais ecoam nos agentes judiciais que têm autoridade para investigá-los, defendê-los ou acusá-los, estabelecendo entre eles pontes de ordem moral. O "bairro" e a "crença" atravessam o balcão, as mesas e os corredores que, ideal e fisicamente, separam agências e agentes públicos daqueles que são objeto de suas ações e decisões, conectando promotores, defensores e juízes a "imputados", "testemunhas" e outros envolvidos em processos variados.

Para analisar tais conexões, a autora lança mão do conceito de "moralidades situacionais". Com ele, dá conta dos valores e interesses associados às histórias de vida, às relaçõos sociais, às perspectivas profissionais e às posições institucionais que, a 
um só tempo, tanto aproximam agentes judiciais das pessoas e conflitos enredados nos processos que lhes cabem, como, nesse mesmo movimento, servem-lhes de guia para investigar "fatos", interpretar "provas" e tomar decisões no âmbito desses mesmos processos. Como regiōes morais transfronteiriças e contextuais, as "moralidades situacionais" de que fala Eilbaum cruzam os limites ideais entre Judiciário e sociedade. Ao mesmo tempo, porém, não os desfazem. Afinal, como mostra a autora, agentes judiciais não se orientam por essas "moralidades" em detrimento das regras e dos procedimentos formais estruturantes de seu campo de atuação. Ao contrário, regras são mantidas e seguidas à risca, mas não de forma neutra, despersonalizada e descontextualizada, e sim de modo a garantir legitimidade e revestir de validade interesses e valores "situacionais".

$\mathrm{Na}$ conformação de "moralidades situacionais" desempenha papel crucial a "crença" dos agentes judiciais, mas não apenas deles, naquilo que dizem os vários personagens dos processos criminais - personagens dentre os quais se destaca o "bairro". Mais que cenário, contexto ou coordenada geográfica, o "bairro" é protagonista de alguns processos administrados pela justiça da província de Buenos Aires. O que o "bairro" diz, a depender da credibilidade de que é revestido, é muitas vezes ouvido, acolhido e reforçado por agentes e procedimentos judiciais, determinando decisões e destinos de pessoas como Marisa e Carlos. Não foi sem sentido, afinal, que a mãe dos gêmeos Rodrigo e Sabrina afirmou, em plena UFI K, que "o bairro fala".

A perspectiva analítica sustentada por Eilbaum, bem como a atenção prestada às categorias nativas "bairro" e "crença", são apresentadas em "O Bairro Fala" ao longo de oito capítulos. Todos são subdivididos em partes relativamente curtas que tornam a leitura ágil e permitem ao leitor produzir e acumular, em pequenos passos, conhecimento sobre o que pode significar "fazer justiça" em Los Pantanos. Os capítulos agrupam-se da seguinte forma: enquanto o primeiro introduz o leitor na etnografia, convidando-o a experimentar os desconfortos, os limites e as possibilidades tanto de "testemunhar", como de pesquisar em contextos judiciais, os dois seguintes descrevem o contexto judicial específico em que teve lugar a pesquisa: por um lado, o conurbano bo- naerense, o sistema de justiça criminal da província de Buenos Aires e o cenário social e político que os envolvem (capítulo 2), e, por outro, a repartição específica em que a autora realizou trabalho de campo - a UFI K (capítulo 3).

No capítulo 2, Eilbaum não se restringe a apresentar aquele sistema de justiça, mas trata também das mudanças e permanências políticas e administrativas que caracterizam a justiça do conurbano, bem como dos contrastes entre ela e a Justiça Federal argentina. Ademais, explora conversas que a estrutura do sistema suscita entre agentes judiciais, reveladoras de sua maleabilidade. A estrutura da justiça criminal no conurbano, mostra a autora, "encerra as concepções e ideologias das pessoas que nela habitam, suas valoraçōes sobre a natureza dos casos que tratam, das atividades que desenvolvem e da importância atribuída a cada uma dessas dimensões" (p. 94). Em sentido semelhante, no capítulo 3 a autora trata a UFI K não simplesmente como uma repartição definida por regras e atribuições legais. Explicitando o que dá "carne e sangue" à Unidad, Eilbaum apresenta as histórias de vida e trajetórias profissionais de seus funcionários, além de explorar o controle de impressões estabelecido entre ela, pesquisadora, e eles, agentes judiciais, no começo de seu trabalho de campo.

Já os capítulos 4 e 5 detêm-se sobre temporalidades específicas que marcam o ritmo de trabalho da UFI K. No capítulo 4, a autora trata do turno, espécie de plantão que ocorre a cada 40 dias e exige que a Unidad esteja de prontidão 24 hs por dia, durante três dias seguidos. Estar de prontidão, ali, implica estar disponível para receber e investigar denúncias de crimes ocorridos na área, seja da parte de policiais, seja através da Oficina de Denúncias ativa na justiça criminal do conurbano. $\mathrm{O}$ principal procedimento levado a cabo no turno é a tomada de depoimento do "imputado", conhecida como "308" (em referência ao artigo do Código de Processo Penal Provincial que o regulamenta). Vale destacar que, para tratar dos "308" que acompanhou, a autora explora, de modo bastante perspicaz, os usos, sentidos e desdobramentos de uma decisão corrente na UFI $\mathrm{K}$, tomada por muitos "imputados": a escolha por "não depor". No capítulo 5, então, Eilbaum dedica-se ao chamado 
"pós-turno", quando são tomados depoimento de "vítimas" e "testemunhas" de processos. Em conjunto, nestes dois capítulos a autora reflete sobre a produção de "crença" na tomada de depoimentos por funcionários da UFI K e, ainda, sobre as diferenças entre "falar" e "depor" e sobre o que a decisão de "não depor" comunica sobre a justiça do conurbano. Nessas reflexōes, o que o "bairro fala" aparece com toda sua força.

Nos três últimos capítulos, porém, o que "o bairro fala" parece ganhar ainda mais eloquência. Eles são dedicados à análise estendida de dois processos específicos acompanhados de modo sistemático por Eilbaum: o caso de Marisa e Carlos, introduzido aqui, e o caso de Cacá - um jovem acusado de matar outro enquanto lhe roubava a motocicleta. Embora ao longo de todo o livro a autora faça referência a diversos processos, o foco pormenorizado nesses dois permite-lhe explorar com fineza "moralidades situacionais" e formas de produção de "crença". Em ambos os processos, "o bairro aparece como uma categoria nativa dotada de significados distintos, mas centrais para entender a trama de relaçôes que deram forma e sustentaram os processos de produção de "provas" e investigação deles" (p. 37). No caso envolvendo Marisa e Carlos, foi determinante o hiato entre o que "o bairro" enunciava como "um valor moral essencial e natural o cuidado maternal - e as atitudes que avaliavam por parte de Marisa” (p. 279); já no caso de Cacá, o "bairro", disputado pelos envolvidos no processo, desempenhou papel central na identificação do "autor" do crime em questão e, ainda, como "fonte legitimadora de versões por meio dele transmitidas perante os funcionários judiciais" (p. 377).

Acumulando qualidades ao longo dos capítulos, "O Bairro Fala" logra analisar com maestria as dinâmicas e interações por meio das quais sentimentos e valores morais não só adentram o universo da administração de justiça, mas também têm a si atribuídos credibilidade e, consequentemente, validade jurídica. Trata-se, portanto, de leitura obrigatória tanto para interessados em antropologia do direito, como para quaisquer pesquisadores dedicados a decifrar a atuação de burocracias, órgãos e programas público-estatais indo além dos ideais de objetividade e racionalidade adminis- trativa que os circundam. Mais do que isso, porém, o trabalho de Eilbaum é leitura recomendável para todo cientista social que, independentemente de seu campo disciplinar e tema de estudo, queira conhecer uma boa etnografia.

\section{LETICIA CARVALHO DE MESQUITA FERREIRA é doutora em antropologia social pelo Museu Nacional/UFRJ e pesquisadora bolsista do CPDOC/FGV. E-mail: <leticiacarvalho@gmail.com>.}

